\title{
Cause of Death
}

National Cancer Institute

\section{Source}

National Cancer Institute. Cause of Death. NCI Thesaurus. Code C81239.

The circumstance or condition that results in the death of a living being. 